\title{
LABORATORY TESTS OF PERMEABLE WAVE ABSORBERS
}

\author{
Lorenz G. Straub \\ Director, St. Anthony Falls Hydraulic Laboratory \\ C. E. Bowers \\ Research Associate, St. Anthony Falls Hydraulic Laboratory \\ John B. Herbich \\ Assistant Professor, Lehigh University
}

\section{INTROLUCTION}

Laboratory studies involving surface waves usually require the use of absorbers at some boundaries of the test facility to prevent objectionable reflections of the test waves. Such absorbers frequently consist of sloping beaches with or without a layer of permeable material. These are sometimes used in conjunction with other devices which absorb part of the wave energy. If sufficient space is available, a long absorber with a low surface slope can be used, resulting in very low reflections. However, space limitations sometimes necessitate the use of an absorber of minimum length with a steeper surface slope. In such cases permeable materials are highly jeneficial to assist in absorbing the wave energy.

While absorbers have been utilized in most laboratories performing wave studies, very little quantitative information has been published on the subject. The majority of data that are available have been obtained in connection with studies of beaches, breakwaters, and other field installations, but they are of interest in the design of laboratory absorbers.

The studies described herein had as their objective the procurement of additional basic information to assist in the design of an absorber for a specified range of wave conditions.

\section{EARLTER STUDIES}

A review of earlier work revealed one theoretical development by Miche (1944) which was considered of interest in this study. Considering the ideal case of a smooth barrier or beach forming an angle $\alpha$ with the horizontal, he developed analytically a formula for the maximum wave steepness (in deep water) which will be totally reflected by such a barrier.

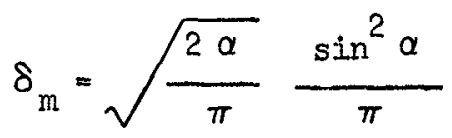

From this he deduced that waves steeper than $\delta_{m}$ would be partially reflected and that the theoretical reflection coefficient $R^{\prime}$ would be 

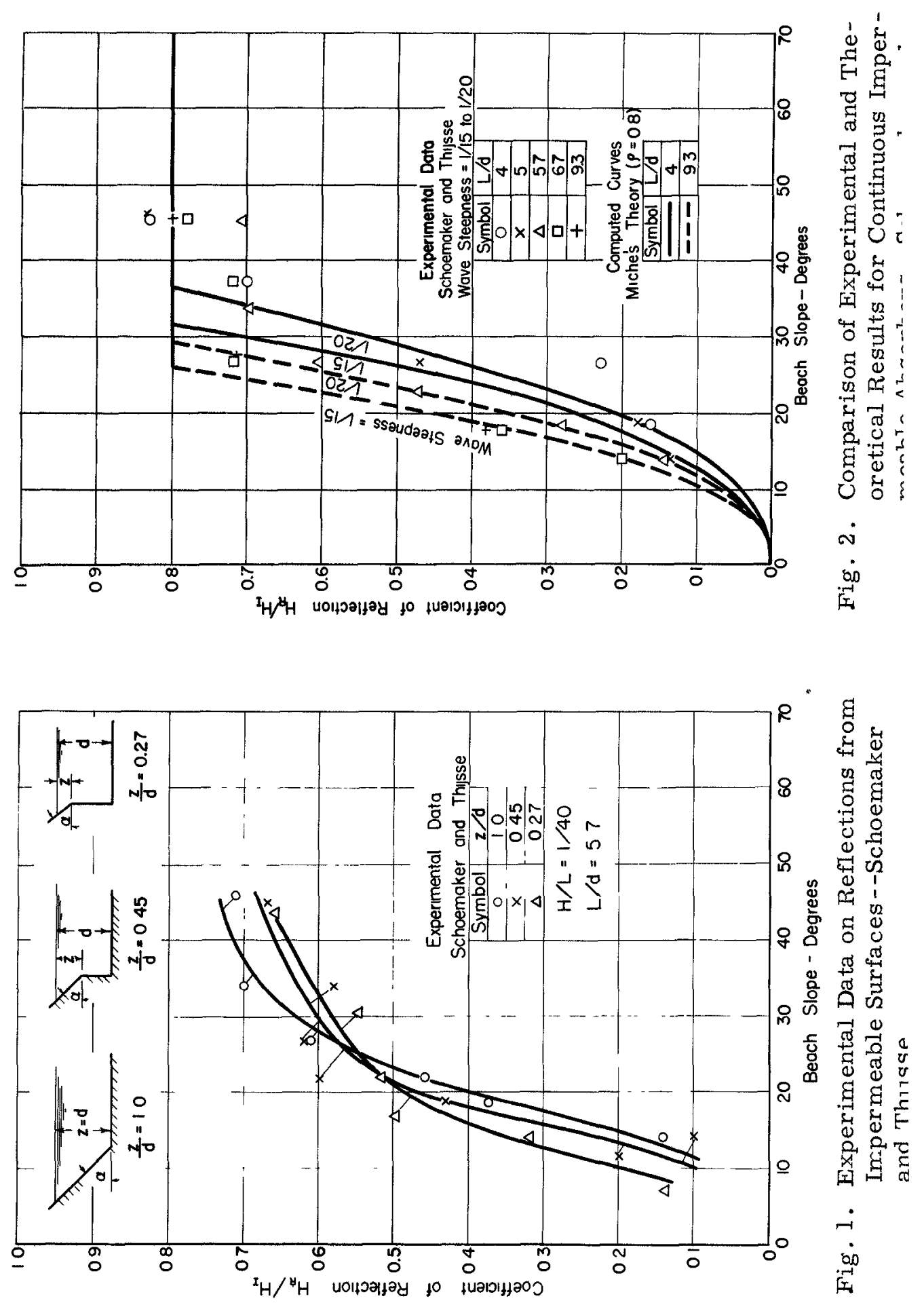


$$
R^{\prime}=\frac{\delta_{m}}{\delta_{0}} \text {, with } R^{\prime} \leqq I,
$$

where $\delta_{0}$ is the incident wave steepness in deep water.

One of the boundary conditions for the theoretical development was based on the assurmption of zero normal velocity at the surface of the barrier or that the barrier was impermeable. To account for permeability as well as roughness of actual installations, Miche introduced an intrinsic coefficient $\rho$ which was assumed to be independent of the beach slope. The actual reflection coefficient was then given as

$$
R=\rho R^{\prime}=\rho \frac{\delta_{m}}{\delta_{0}}=\frac{H_{R}}{H_{I}},
$$

where $H_{R}$ is the reflected wave height and $H_{I}$ the incident wave height.

In a subsequent publication Miche (1951) indicated that $\rho$ might vary from 0.68 to 1.0 for rough and smooth impermeable barriers, respectively. A value of $\rho=0.32$ was indicated for a rubble mound structure.

Schoemaker and Thijsse (1949) published the results of a series of experimental studies on walls with both contimuous and discontinuous slopes. The discontimuous slopes were formed by a lower vertical wall and an upper sloping section; the point of juncture was positioned at various distances below the still water surface.

Figure 1 illustrates data obtained by Schoemaker and Thijsse for one value of wave steepness and one wave length. The curves for the three types of models tested are fairly close together, but greater differences can probably be expected for shorter waves.

Figure 2 illustrates additional data for length-to-depth ratios from 4 to 9.3 ; it was indicated that the wave steepness varied from 0.05 to 0.067 . Curves based on Wiche's theory have been plotted on the same figure for comparative purposes; a coefficient $\rho$ of 0.8 appeared to give the best agreement between the experimental data and the computed curves. The experimental data are for a continuous slope $(\mathrm{z} / \mathrm{d}=1)$.

The Beach Irosion Board (1949) published data on the reflective characteristics of various simple structures based on tests with solitary waves. Both permeable and impermeable structures were tested. The porosity of some of the structures was varied; it was concluded that the best absorption was obtained with a porosity of 60 to 80 per cent. In tests of a porous rock wall backed by open water with both faces of the wall vertical, it was found that the maximum absorption was obtained when the length of permeable material was 2.5 times the water depth. 
COASTAL ENGINEERING
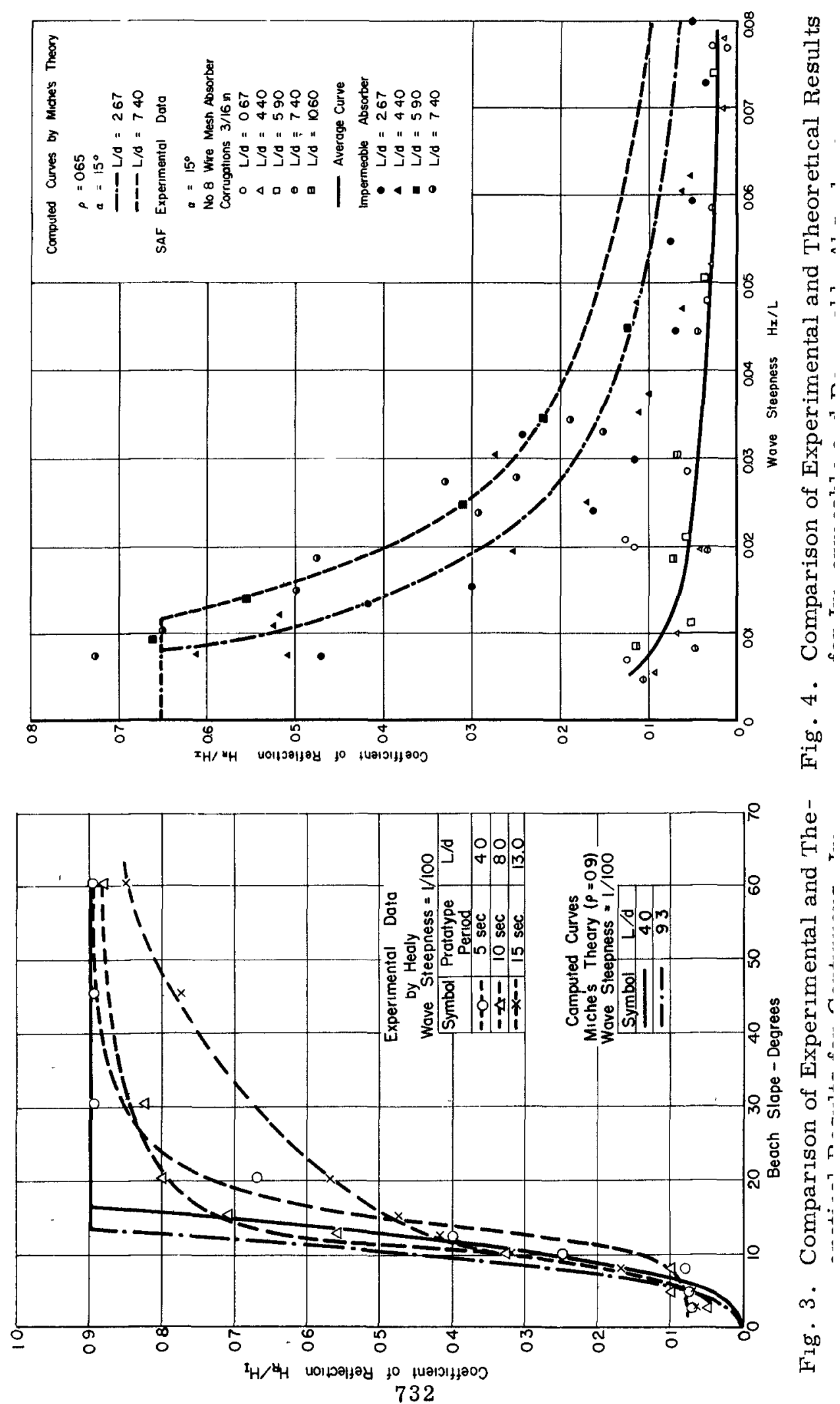


\section{LABORATORY TESTS OF PERMEABLE WAVE ABSORBERS}

Laurent and Devimeux (1951) published the results of studies of reflections from several types of seawalls. They concluded that the reflecting capacity of a seawall varies inversely as a function of the wave steepness and that reflections decreased with a decrease in wall slope.

Healy (1953) presented experimental data on reflections from sloping impermeable beaches made of smooth plywood. Values of wave steepness from 0.005 to 0.025 , beach slopes from 2 degrees to 60 degrees, and prototype wave periods of 5,10 , and $15 \mathrm{sec}$ were used in the tests. Figure 3 illustrates some of the data obtained by Healy with two comparative computed curves based on Wiche's theory. Other data indicated a decrease in reflection coefficient from 0.67 to 0.16 as the wave steepness increased from 0.003 to about 0.017 for a 10-degree slope.

While the preceding experiments were very helpful in the study of impermeable structures, the lack of data on the reflections of oscillatory waves from permeable structures necessitated additional experimental work. As a result a series of tests was conducted on permeable materials of various types with a few additional check tests on impermeable sloping surfaces.

\section{TEST EQUIPIINT AND PROCEDURE}

The major portion of the experimental studies were conducted in a wave channel $6 \mathrm{in}$. wi.de, $15 \mathrm{in}$. deep, and $40 \mathrm{ft}$ long. Subsequently some check tests were performed in a larger facility with a width of $9 \mathrm{ft}$, a depth of $6 \mathrm{ft}$, and a length of $253 \mathrm{ft}$.

Waves were generated by a pendulum-type generator in the small facility and by a hinged-plate generator in the large facility.

Wave heights were measured by a capacitive wave-profile recorder. The probe of this recorder was traversed over a distance of at least one-half wave length, giving a record of the envelope of the standing wave or partial clapotis which resulted fron addition of the incident and reflected waves. The reflection coefficient $R$ and incident wave height $\mathrm{H}_{T}$ were obtained from the following formulas:<smiles>[R][CH]C([CH])[CH][R]</smiles>

and

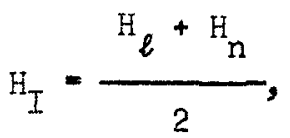




\section{COASTAL ENGINEERING}

where

$\mathrm{H}_{\ell}=$ height at loop

$\mathrm{H}_{\mathrm{n}}=$ height at node of standing wave

These can be developed by addition of equations for the surface profile of the incident and reflected waves, using an assumed sine profile.

The reflections were measured over a length of about $3 \mathrm{~d}$ to $3 \mathrm{~d}+$ $I / 2$ from the toe of the absorber; preliminary tests indicated that the maximum reflections were obtained by measuring in this zone.

\section{EXXPETMENTAL PROGRAM AND DATA}

The experimental studies included measurements of wave reflection for variations in the slope, shape, and porosity of the absorber and variations in the length-to-depth ratio and steepness of the incident waves.

Initially, data were obtained on a permeable material consisting of corrugated wire mesh with a porosity of about 93 per cent. This was followed by tests on absorbers of gravel, crushed rock, and perforated plates. Finally, limited tests were performed on absorbers made up of transverse square rods, spaced to produce a porosity of about 70 per cent. Brief tests were also conducted on impermeable surfaces for comparison with theory and the data of others; this was considered desirab: as a check on the test procedure.

Values of wave steepness ranging from 0.005 to 0.08 and length-todepth ratios ranging from about 0.6 to 10.0 were used during the various phases of the tests, although this range was restricted in some instance

Figure 4 illustrates experimental data for permeable and impermeab] absorbers with a 15-degree surface slope. Two curves based on Niche's theory have been included for comparative purposes. Good agreement between theory and experiment for the impermeable surface was obtained for wave steepness less than 0.03 . However, for values of wave steepness on the order of 0.06 to 0.08 the measured reflections were about half the theoretical values.

As may be noted in Fig. 4, the permeable absorber was considerably superior to the impermeable unit, although the total length required for the two types was the same.

During the tests of both continuous and discontinuous slope absorbe it was found that the curves of reflection as a function of steepness, slope, or wave length frequently were not smooth curves due to secondary variations. Some of these variations were apparently caused by addition and cancellation of reflections from two or more parts of the absorber. With the impermeable absorber, some variation resulted from waves generated by water returming to the normal level following the initial uprush due to breaking of the wave. The resultant wave or reflection was sometimes of an appreciable magnitude even though complete breaking of the incident wave occurred. A relatively thin layer of permeable material was sometimes quite beneficial in alleviating this effect. 


\section{LABORATORY TESTS OF PERMEABLE WAVE ABSORBERS}
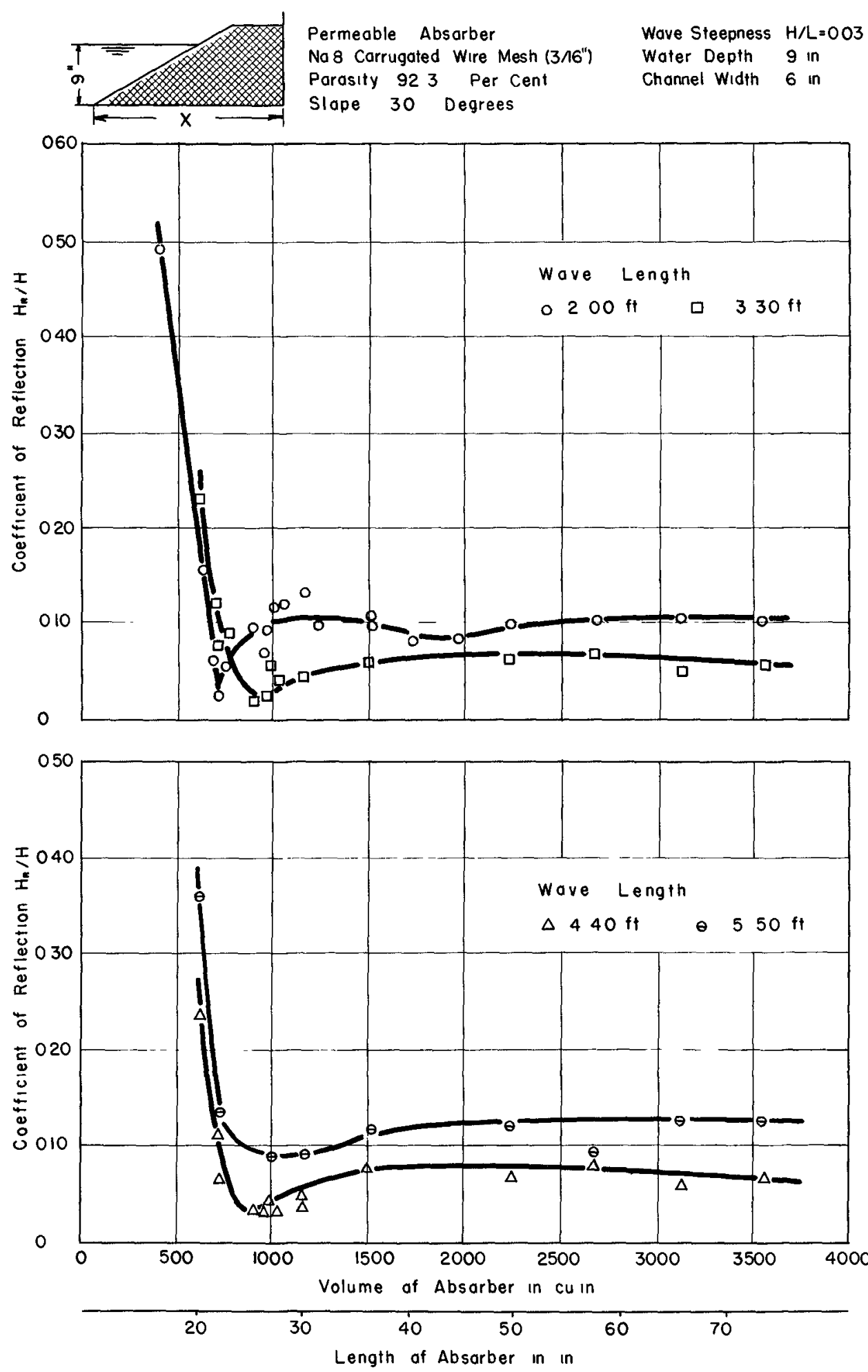

Fig. 5. Effect of volume on coefficient of reflection for a wiremesh absorber. 
COASTAL ENGINEERING
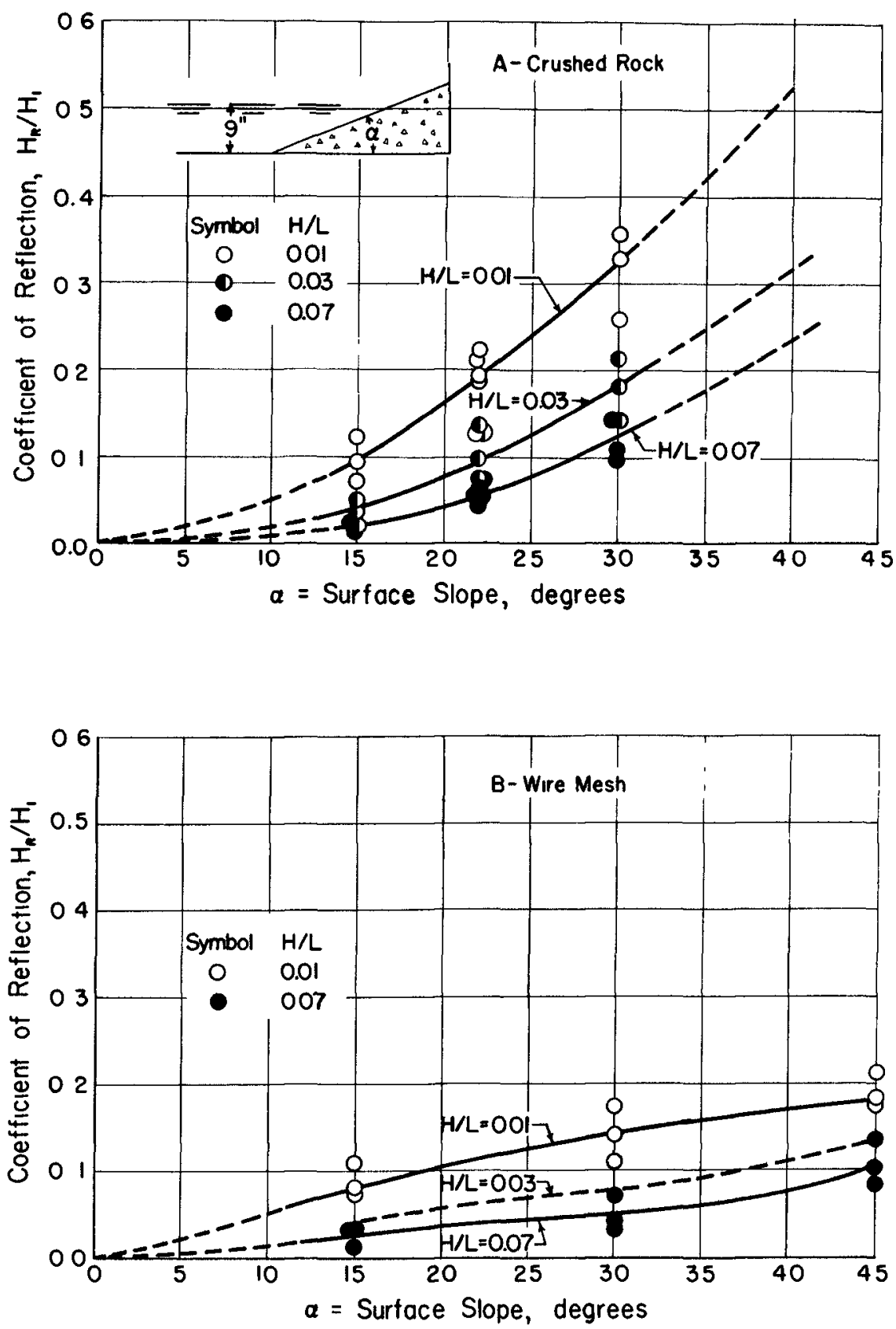

Fig. 6. Reflection coefficients for crushed-rock and wiremesh absorbers. 


\section{LABORATORY TESTS OF PERMEABLE WAVE ABSORBERS}

During the tests of wire-mesh absorbers, which had a high porosity, it was noted that an appreciable orbital motion occurred well back in the permeable material. As a check on the effect of variations in the length or volume of permeable material, a brief series of tests was performed with absorbers of various length or volume with a constant surface slope. A steep slope of 30 degrees was selected for the tests. Figure 5 illustrates typical data on the effect of variation in length or volume of the absorber for a wave steepness of 0.03 . The minimum allowable length was well defined by a very steep portion of the curve of reflection as a function of absorber length. With a further increase in length, the reflections increased slightly and then remained relatively constant in spite of large increases in volume of permeable material. The low point in the curve may have been caused by cancellation of reflections from the sloping surface and vertical backing plate of the absorber. The data are of limited value as the minimum length or volume will vary as a function of the slope and porosity of the absorber, but they are indicative of the effect of variations in volume. Also, the data indicated that low absorption coefficients could be obtained for relatively high values of $\mathrm{L} / \mathrm{d}$ with a short absorber.

Figure 6(a) illustrates experimental data for crushed-rock absorbers with surface slopes from 15 to 30 degrees. The length of the absorbers varied with the slope, but the volume of material used was a constant. Several sizes of rock were used in the tests: $1 / 4$ in. to $3 / 4$ in., 1 in. to $1-1 / 2$ in., and $1-1 / 2$ in. to 2 inches. The narrow size gradation resulted in porosities on the order of 50 per cent. Initial tests were performed with gravel (porosity 40 per cent) and pit-run crushed rock (porosity 45.8 per cent). The reflections for the latter two materials were fairly low, but further improvement was obtained by screening the crushed rock to produce a narrow size gradation and a higher porosity. Accordingly, most of the tests were performed on the screened rock.

In this series of tests the size of rock apparently had little effect on the average reflection coefficient. However, placement of the rock was very imoortant with the result that subsequent tests with the same material produced variations in the reflection coefficients up to 100 per cent. These variations were more pronounced with the larger size ranges.

The data in Fig. 6(a) were obtained with test wave lengths ranging from 2 to $4.4 \mathrm{ft}(\mathrm{I} / \mathrm{d}=2.67$ to 5.85$)$. Variations as a function of wave length were noticeable in this range for a single absorber; however, such variations were less than those due to placement of the rock. As a result, an average curve is shown. With a discontinuous absorber the variations in wave length have a much greater effect.

The coefficient $\rho$ in Miche's formula was computed for the crushed-rock absorbers. It varied from about 0.11 with a wave steepness of 0.01 to about 0.19 with a wave steepness of 0.07 . For comparative purposes, the coefficient for the impermeable absorbers varied from about 0.65 with a wave steepness of 0.01 to about 0.35 with a wave steepness of 0.07 . 


\section{COASTAL ENGINEERING}
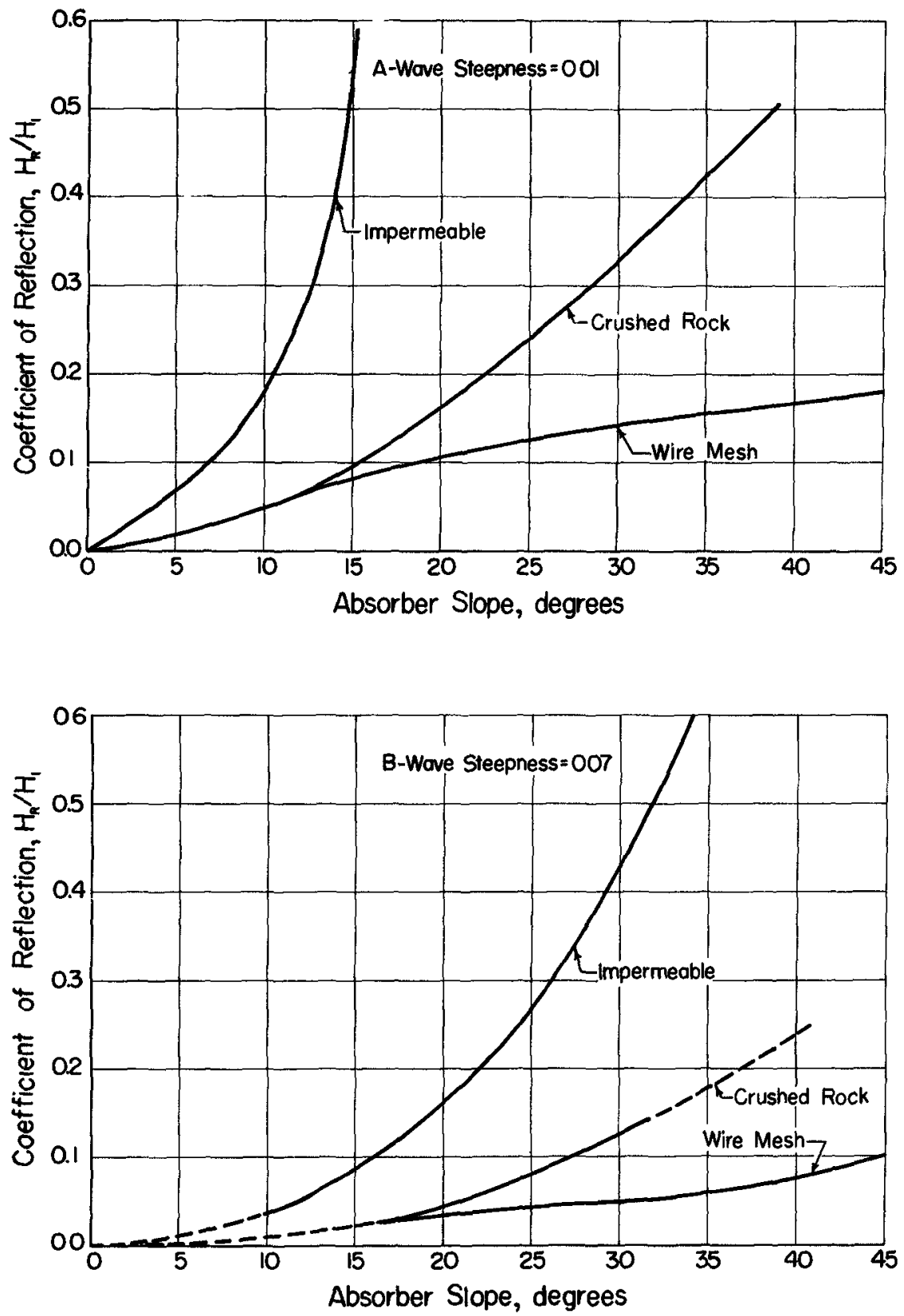

Fig. 7. Comparison of impermeable, crushed-rock, and wire-mesh absorbers . 


\section{LABORATORY TESTS OF PERMEABLE WAVE ABSORBERS}

Reflection coefficients for continuous-slope wire-mesh absorbers are plotted in Fig. 6(b) for two values of wave steepness. Average values are shown for wave lengths ranging from 2.0 to $4.4 \mathrm{ft}$. The absorbers were constructed of alternate layers of corrugated and plain wire mesh. The corrugations had a total height of $3 / 16$ inches. The mesh had a spacing of 8 wires per inch. The porosity of this arrangement was about 93 per cent.

The curves of reflection as a function of absorber slope are similar to those for crushed rock for slopes less than 15 degrees. For slopes in excess of 15 degrees the wire-mesh absorbers were considerably more efficient than the crushed-rock absorbers. The coefficient $\rho$ varied from about 0.09 with a wave steepness of 0.01 to about 0.19 with a wave steepness of 0.07 for a surface slope of 15 degrees.

Figure 7 illustrates comparative curves of reflection coefficient as a function of slope for the three types of contimuous absorbers: impermeable, crushed rock, and wire mesh.

Following the above tests, studies were made of absorbers consisting of a layer of permeable material over an impermeable surface. With water depths of 9 and $12 \mathrm{in}$. and wave lengths ranging from 2 to $4.4 \mathrm{ft}$, reflection coefficients of about the same magnitude as those shown in the preceding graphs were obtained for a thickness of permeable layer of about 3 inches. A thickness in excess of this value was not beneficial; a lesser thickness usually resulted in higher reflections. However, this thickness cannot be considered as a fixed value as it depends to a considerable extent on the range of wave lengths of interest.

On the basis of these studies, it was concluded that a material with a high porosity was desirable if an absorber of minimum length was needed. Wire mesh is only one of the possible materials which might be used. Others include perforated plates and metal shavings. However, the cost of such materials would be prohibitive in many installations, and cheaper materials, such as crushed rock or cast concrete products, may be desirable. With low surface slopes crushed rock with a narrow size gradation is almost as good as the mesh or other metal products except for variations which result if the material is packed or laid so as to produce a low porosity. In an effect to reduce cost and silil achieve uniformity, tests were performed on a system of square, concrete bars, spaced to produce a porosity of about 70 per cent. The bars were laid with their main axis horizontal and transverse to the direction of wave propagation. Square bars were selected, in preference to other shapes, to reduce variations in the drag coefficient due to viscous effects. This was considered desirable to avoid serious scale effects. Tests were performed on a series of discontimuous absorbers designed for shorter wave lengths than the tests described above. The reflection coefficients were much more consistent than those obtained with crushed rock, and average coefficients were somewhat superior to crushed rock.

The majority of data presented in this paper have been restricted to continuous absorbers or beaches with the thought that this configuration would be of primary interest. However, one illustration of $\exists$ discontimous absorber may also be of interest. Absorber A in Fig. 8 


\section{COASTAL ENGINEERING}

\section{ABSORBER CHARACTERISTICS}

\section{Absorber A}

Discontinuous, Permeable

Thickness of Permeable Layer 785 in

Seven Layers of Bars

Stope 12 , Degrees

Porosity 67 Percent

Chonnel Width $9 \mathrm{ft}$
Absorber B

Continuous, Partly Permeabie

Same as Absorber A Except

Impermeable Beach Added in Front

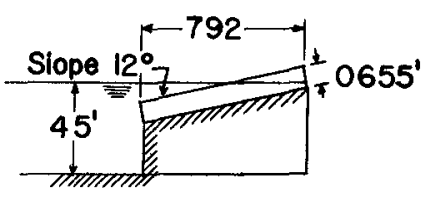

Absorber $\mathbf{A}$

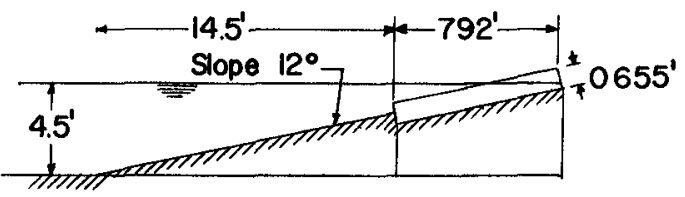

Absorber B

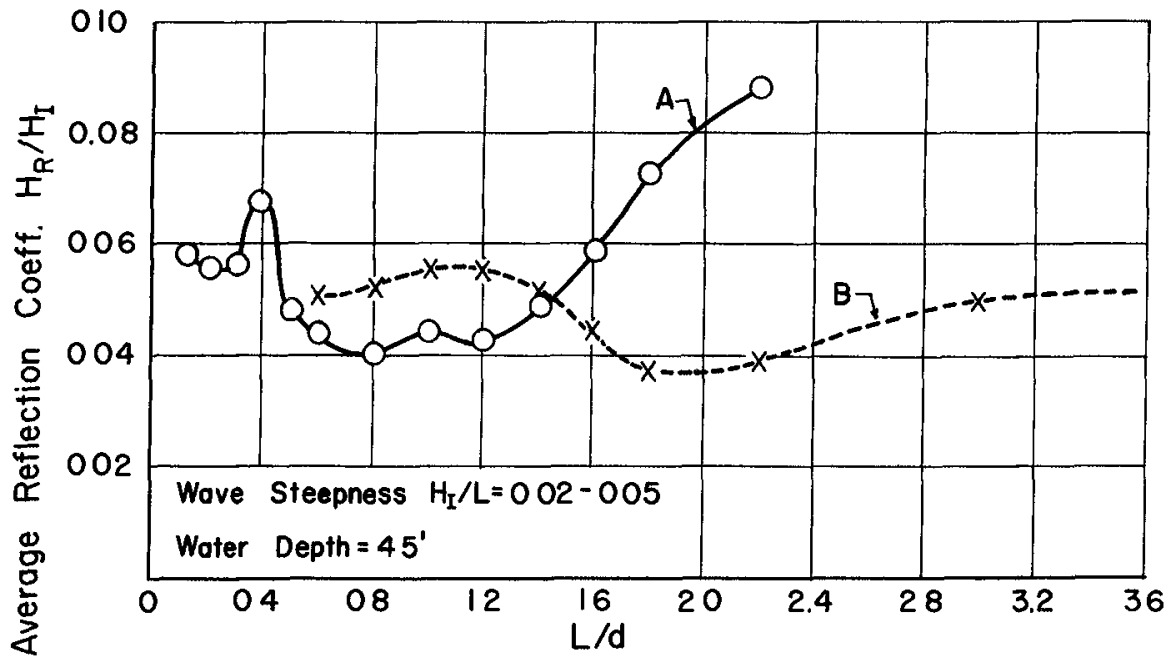

Fig. 8. Comparative reflection coefficients for continuous and discontinuous absorbers. 


\section{LABORATORY TESTS OF PERMEABLE WAVE ABSORBERS}

illustrates a discontimuous absorber developed for a range of $\mathrm{L} / \mathrm{d}$ values from 0.15 to 2.0. The maximum allowable length of the absorber was $1.8 \mathrm{~d}$. Initial tests were performed in the small wave channel; following a preliminary selection of the basic geometry, tests were performed in the large channel with various thicknesses of permeable material over an impermeable surface. Cmushed rock and square bars were used as permeable material.

The reflection curve shown for Absorber $A$ is an average of the range of wave steepnesses of primary interest for the square-bar construction. For $I / d$ values less than 1.6 some variation in the reflection coefficient occurs, probably due to addition of multiple reflections. For $\mathrm{L} / \mathrm{d}$ values above 1.6 the curve has a pronounced upward trend indicating increased reflections from the lower part of the absorber. Addition of a vertical layer of permeable material on the lower face was slightly beneficial but did not warrant the increased cost. For comparative purposes a section was added to produce a continuous absorber--Absorber B of Fig. 8. The average curve for this unit has some minor variations but can be considered relatively independent of wave length for $I / d$ values up to about 3.6. For $I / d$ values less than 1.6 this unit was comparable to the discontinuous unit even though it had triple the length of the latter.

Figure 9 illustrates reflection coefficients obtained in smalland large-scale model tests of the discontimuous absorber plus data obtained by the Navy on a prototype section. The square-bar permeable material was used in all three models. Agreement was considered very good and Indicated little, if any, scale effect.
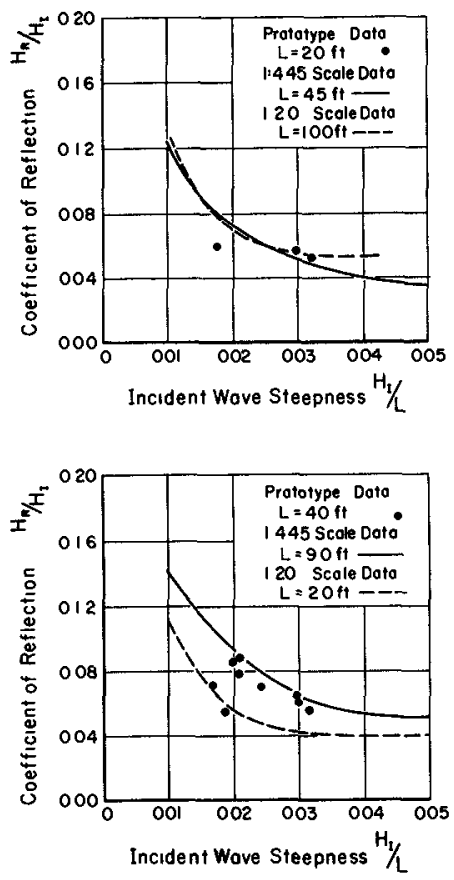

Fig. 9. Comp rison of Reflection Data Obtanned in Two líodels and a Prototype Absorber. 


\section{COASTAL ENGINEERING}

\section{ACKNOWLEDGMENT}

The tests described herein were sponsored by the David Taylor Model Basin, Department of the Navy.

\section{REFERENCES}

Iliche, M. (1944). Mouvement ondulatoires de la mer en profondeur constante ou décroissante: Annales des Ponts et Chaussées.

Miche, I. (1951). The Reflecting Power of Maritine Works Exposed to Action of the Swell: Annales des Ponts et Chaussees. Abstract in Bulletin of the Beach Erosion Board, Vol. 7, No. 2.

Schoemaker, H. J. and J. Th. Thijsse (1949). Investigations of the Reflection of Waves: Proceedings of the Third Meeting of the International Association for Hydraulic Stmuctures Research, Grenoble.

Beach Erosion Board (1949). Reflection of Solitary Waves: Beach Eirosion Board Technical Report No. 11.

Laurent, J. and Devimeux, w. (1951). Étude Expérimental de la Réflexic de la Houle sur des Obstacles accores: reprint from Revue Génera: de L'Hydraulique, No. 65.

Healy, J. J. (1953). Wave Damping Effect of Beaches: Proceedings of Minnesota International Hydraulics Convention, Minneapolis, Hinnesota. 